\title{
PÓS-GRADUAÇÃO LATO SENSU: APONTAMENTOS PARA A GESTÃO ESTRATÉGICA A PARTIR DAS EXPECTATIVAS DOS CANDIDATOS ${ }^{1}$
}

\author{
Marcos Antônio Alves ${ }^{2}$ \\ Cristiano Lopes Carvalhaes \\ Paulo Roberto de Sousa
}

\begin{abstract}
RESUMO
O objetivo deste artigo foi analisar o perfil de candidatos a cursos de Pós-Graduação Lato Sensu e identificar pontos estratégicos para uma melhor condução do curso e aprendizagem do aluno. Um questionário foi aplicado e continha questões demográficas e outras relacionadas com as expectativas da formação, motivos para cursá-la e critérios de decisão. Um total de 136 candidatos foram entrevistados e eles externaram a importância de cada item em uma escala Likert de 1 a 9 pontos. Os resultados indicaram que dentre os candidatos entrevistados, a maioria compreendeu: homens (61.03\%), entre 20 e 29 anos (49.26\%), solteiros (61.03\%), que concluíram graduação (94.11\%) em instituições privadas (75\%) entre 2016-2015 (26.47\%) ou 2014-2011 (37.5\%). A formação é buscada por iniciativa própria e eles demonstraram alta expectativa quanto à formação teórica e profissional. Módulos comuns para diferentes cursos, ações de marketing aproveitando as oportunidades de mercado, descontos para ex-alunos de graduação e especialização e currículo voltado ao mercado foram as principais proposições percebidas e discutidas. Este trabalho retoma um tema de grande importância para a educação superior, fornece uma revisão normativa histórica e pode servir de apoio para gestores educacionais, empresas privadas e pesquisadores envolvidos nesta formação.
\end{abstract}

Palavras-chave: Pós-Graduação Lato Sensu. Especialização. Educação superior. Perfil do candidato.

\section{LATO SENSU POSTGRADUATE COURSES: STRATEGIC MANAGEMENT BASED ON CANDIDATES' EXPECTATIONS}

\begin{abstract}
The aim of this paper was to analyze the profile of candidates for Lato Sensu Postgraduate courses and to identify strategic points for a better conduction of the course and students learning. A survey was conducted with demographic and course expectations questions, considering the reasons for taking it and decision-making. A total of 136 candidates were interviewed and they expressed the importance of each item on a 1-9 point Likert scale. The results indicated that among the candidates interviewed, the majority were: men $(61.03 \%)$; 20 29 years old $(49.26 \%)$; single $(61.03 \%)$; who completed their undergraduate degree $(94.11 \%)$; in private institutions (75\%); between 2016-2015 (26.47\%) or 2014-2011 (37.5\%). The graduation is sought on their own initiative and they showed high expectations regarding

\footnotetext{
${ }^{11}$ Como citar este artigo: ALVES, M. A.; CARVALHAES, C. L.; SOUSA, P. R. de. Pós-graduação Lato Sensu: apontamentos para a gestão estratégica a partir das expectativas dos candidatos. ForScience, Formiga, v. 8, n. 2, e00858, jul./dez. 2020. DOI: 10.29069/forscience.2020v8n2.e858.
}

${ }^{2}$ Autor para correspondência: Marco Antônio Alves, e-mail: m.voicer@gmail.com
\end{abstract}


theoretical and professional training. Common modules for different courses, marketing actions taking advantage of market opportunities, discounts for undergraduate and specialization students and curriculum aimed at the market were the main proposals perceived and discussed. This research takes up a topic of great importance for higher education, provides a historical normative review and may be used as support for educational managers, business and researchers involved in this field.

Keywords: Lato Sensu Postgraduate Courses. Specialization. Strategic Management. Candidates' Profile.

\section{INTRODUÇÃO}

A busca por cursos de Pós-Graduação Lato Sensu (PGLS) tem crescido ao longo dos anos. A graduação deixou de ocupar um nível de destaque que antes era considerado como diferencial no mercado de trabalho. As especializações, de uma forma geral, surgiram com o objetivo de oferecer extensão acadêmica para potencializar a qualificação dos participantes. A possibilidade de aliar a teoria e a prática somadas à interação e contato entre alunos e professores tornaram atrativas esta formação eximindo do candidato as responsabilidades e dedicação exigidas nos cursos Stricto Sensu.

Atualmente a PGLS compreende os cursos de Especialização e Master Business Administration (MBA) e devem possuir carga horária mínima de 360 horas (BRASIL, 2020a). Tais cursos podem ser ofertados por: a) instituições de educação superior (IES) devidamente credenciadas para oferta de cursos de graduação presencial ou a distância; b) instituições de qualquer natureza que ofereça cursos stricto sensu avaliados pela Coordenação de Aperfeiçoamento de Pessoal de Nível Superior (CAPES) e autorizado pelo Conselho Nacional de Educação (CNE); c) escola de governo (EG) criada e mantida por instituição pública; d) instituições que desenvolvam pesquisa científica ou tecnológica; e) instituições relacionadas ao mundo do trabalho de reconhecida qualidade, conforme normas estabelecidas na Resolução ${ }^{\circ}$ 1, de 06 de abril de 2018 (BRASIL, 2018).

Entretanto, pouca legislação vigora sobre a PGLS e, apesar da ausência de uma identidade conceitual apontada por Fonseca (2004), Pilati (2006), Mazon et al. (2012) e Fonseca e Fonseca (2016), o número de cursos de especialização tem aumentado ao longo dos anos, sendo maior nas IES privadas (MAZON et al., 2012; FONSECA; FONSECA, 2016) gerando a mercantilização dos cursos (SPAGNOLO; SEVILLA, 1994).

A PGLS tem sido procurada por um grande número de candidatos que visam melhor qualificação para se moldar e sobressair no mercado de trabalho. Porém, questões como 
ALVES, M. A.; CARVALHAES, C. L.; SOUSA, P. R. de. Pós-graduação Lato Sensu: apontamentos para a gestão estratégica a partir das expectativas dos candidatos

insuficiência de dados e falta de caracterização dos cursos e o público-alvo (isto é, delinear o perfil de pessoas que buscam por esta formação) dificultam debates e avanços na área (SPAGNOLO; SEVILLA, 1994; PILATI, 2006; NASCIMENTO et al., 2014; FONSECA; FONSECA, 2016). Além disso, Nascimento et al. (2014) verificaram que os interessados em ingressar em um curso de PGLS não dispõem de mecanismos hábeis para os auxiliarem na tomada de decisão. Para isso, os autores sugerem que os candidatos interessados em um curso lato sensu devem, antes de contratá-lo, fazer uma opção com base nas suas expectativas e só então avaliar o melhor custo-benefício. Por outro lado, é sabido que muitas variáveis podem ser relacionadas à gestão estratégica destes cursos e cada uma delas trazer diferentes níveis de expectativas entre os candidatos.

Diante do exposto, este artigo busca fazer contribuições à PGLS por meio de uma análise e identificação do perfil de candidatos e suas expectativas quanto à formação em cursos de Especialização e MBA. A PGLS foi escolhida como proposta de resgatar o tema, considerando sua contribuição ao mercado de trabalho e aprofundamento do saber como modalidade pós-graduada, como destacaram Pilati (2006), Freitas e Cunha (2009), Pires e Puggian (2014) e Fonseca e Fonseca (2016). O método de coleta de dados foi um questionário inspirado na literatura. Posteriormente, as variáveis pesquisadas foram discutidas de forma a apresentar proposições à gestão dos cursos PGLS.

Argumenta-se que este trabalho torna-se relevante em vários aspectos, quais sejam: a) discute um tema de fundamental importância para a comunidade científica e que afeta diretamente o mercado de trabalho; b) fornece um histórico curto, detalhado e atualizado da PGLS no Brasil; c) analisa e discute uma base para construção do perfil do candidato a cursos pós-graduados; d) apresenta as variáveis para um questionário fiável e que pode ser utilizado por outros pesquisadores; e e) indica às IES o perfil do candidato a um curso de Especialização ou MBA, visto a dificuldade de atingir este público.

\section{FUNDAMENTAÇÃO TEÓRICA}

\subsection{Histórico da Pós-Graduação Lato Sensu}

No Brasil, Romero e Lopes (2002) destacaram que o estímulo à extensão universitária se fez presente a partir de meados do século XX. Com o aumento da quantidade de escolas superiores, foi necessário sistematizar as atividades de estudos posteriores à graduação. $\mathrm{O}$ 
ALVES, M. A.; CARVALHAES, C. L.; SOUSA, P. R. de. Pós-graduação Lato Sensu: apontamentos para a gestão estratégica a partir das expectativas dos candidatos

objetivo era que esta nova formação gerasse novos conhecimentos, transpondo o saber adquirido com a graduação.

Para Freitas e Cunha (2009), o grande marco regulatório da PGLS ocorreu a partir de 1961 quando foi promulgada a Lei de Diretrizes e Bases da Educação Nacional - Lei no 4.024 de 20 de dezembro de 1961 (LDB/61), que posteriormente fora revogada pela Lei $\mathrm{n}^{\circ}$ 9.394/96. Os autores mencionaram que antes disso havia apenas menções a este tipo de curso. No entanto, a LDB/61 não trazia de forma clara a definição sobre os cursos de especialização, aperfeiçoamento e extensão, possibilitando ambiguidade e generalizações no seu entendimento. Em 1965 foi emitido o Parecer 977 que definia e caracterizava a PGLS no Brasil e fixava normas gerais para sua organização e funcionamento (OLIVEIRA, 1995). Este ditame distinguia, explicitamente e pela primeira vez, os cursos de pós-graduação entre Stricto Sensu e Lato Sensu (ROMERO; LOPES, 2002; SAMWAYS FILHO, 2003; PILATI, 2006; FREITAS; CUNHA, 2009; PIRES; PUGGIAN, 2014). O primeiro era voltado para Mestrado e Doutorado e o último passaria a abranger os cursos de Especialização e Aperfeiçoamento. Por meio deste Parecer, a Capes informou que a meta para os cursos Lato Sensu era permitir ao aluno o domínio científico e técnico de certa e limitada área do saber ou da profissão para formar o profissional qualificado. A finalidade era fomentar a busca por novos conhecimentos por meio da pesquisa criadora.

Após uma lacuna de 12 anos, em 1977 foi aprovada a Resolução nº 14, que estabeleceu as normas de organização e funcionamento dos cursos. Esta resolução fixou as condições de validade dos certificados dos cursos de especialização e aperfeiçoamento para o magistério superior, porém se restringiu a emitir normas genéricas acadêmicas e curriculares. Em 1983, o Conselho Federal de Educação (CFE) publicou a Resolução $n^{\circ}$ 12, que substituiu a Resolução $n^{\text {o }} 14 / 77$. Freitas e Cunha (2009) consideraram que a Resolução ${ }^{\circ}$ 12/83 ratificava o enfoque dos cursos em relação à carreira docente quando estabeleceu como preocupação central o "aspecto formativo de cursos de aperfeiçoamento e especialização para o magistério superior".

A PGLS teve um importante crescimento a partir de 1990. Fonseca e Fonseca (2016) destacaram que este aumento ocorreu em função do processo de globalização e pela consequente necessidade de capacitação de mão de obra atualizada. Enquanto para Pilati (2006) isso ocorreu, principalmente, para suprir as falhas deixadas pelos cursos de graduação, já que esta formação se apresentava como opção aos programas Stricto Sensu.

Em abril de 2001 a Câmara de Educação Superior do CNE publicou a Resolução no 1 (BRASIL, 2001) que estabeleceu um conjunto de novas normas para o funcionamento de 
ALVES, M. A.; CARVALHAES, C. L.; SOUSA, P. R. de. Pós-graduação Lato Sensu: apontamentos para a gestão estratégica a partir das expectativas dos candidatos

cursos. A partir desta resolução, foram revogadas as anteriores: CFE 5/83, CNE/CES 2/96, 1/97 e 3/99. Para Freitas e Cunha (2009), um dos objetivos desta resolução foi formalizar que os cursos de Especialização deveriam focar nas "expectativas de aprimoramento acadêmico e profissional" e exigia que os cursos fossem supervisionados por órgãos competentes. A referida Resolução ainda trouxe outros pontos importantes para o Lato Sensu: pela primeira vez foram mencionados os cursos de MBAs. Era sabido que o mercado já utilizava esta nomenclatura e a legislação era tardia, porém reconheceram as ofertas de MBAs como cursos de PGLS. A proposta inicial destes cursos era oferecer uma visão generalista sobre gestão empresarial, cujo público alvo inicial deveria possuir experiência em atividades relacionadas a gestão. Embora a nomenclatura seja largamente utilizada para atratividade, segundo o próprio MEC "Os cursos designados como MBA - Master in Business Administration ou equivalentes nada mais são do que cursos de especialização em nível de pós-graduação na área de administração" (BRASIL, 2020a).

Freitas e Cunha (2009) afirmaram que a legislação da PGLS proporcionou a proliferação de cursos de especialização em todo país, sendo que a frágil legislação e supervisão da modalidade fizeram com que as próprias IES desenvolvessem internamente formas de regulação dos cursos, principalmente as privadas, objetivando aumentar o resultado financeiro apenas. Pilati (2006) questionou sobre a qualidade desses cursos e considerou que a PGLS gerou uma "fábrica de certificados".

Após denúncias sobre várias irregularidades na condução da PGLS, em 2004 foi criada uma comissão pelo Ministério da Educação cujo objetivo era acompanhar e supervisionar o cumprimento das disposições da Resolução CES/CNE n 1/01 (FONSECA; FONSECA, 2016). Assim, as instituições foram obrigadas a realizar o cadastro dos cursos e o resultado deste registro de informações foi organizado no Censo da Educação Superior (BRASIL, 2003). Entretanto, este censo foi o único que trouxe números, dados e estatísticas sobre a PGLS. Spagnolo e Sevilla (1994), Pilati (2006) e Fonseca e Fonseca (2016) afirmaram que o crescimento nas ofertas de cursos de PGLS foi negligenciado tanto no aspecto de normatização, quanto pelo processo de avaliação da CAPES.

Para Fonseca e Fonseca (2016) a flexibilidade na oferta dos cursos de PGLS pode ter comprometido a qualidade ao indicarem que a Resolução $n^{\circ} 7 / 2011$, do CNE/CES, extinguiu a possibilidade de credenciamento de instituições não educacionais para a oferta de PGLS. As autoras indicaram que a mencionada Resolução foi uma iniciativa clara de intenção regulatória para preservar uma qualidade mínima desses cursos.

ForScience, Formiga, v. 8, n. 2, e00858, jul./dez. 2020. 
ALVES, M. A.; CARVALHAES, C. L.; SOUSA, P. R. de. Pós-graduação Lato Sensu: apontamentos para a gestão estratégica a partir das expectativas dos candidatos

Em 2014 foi publicada uma nova resolução, Resolução CNE/CES nº 2 (BRASIL, 2014), que tratava a PGLS e, desta vez, o ditame instituiu o cadastro para os cursos presenciais e a distância de toda IES credenciada no Sistema Federal de Ensino. A Resolução traz a informação dos dados que contemplaram o cadastro e determina que cabe à Secretaria de Regulação e Supervisão da Educação Superior do Ministério da Educação (SERES/MEC) como órgão responsável pelo cadastramento e acompanhamento do processo. Em abril de 2018, o MEC publicou por meio da CAPES a Resolução nº 1/2018 com muitas novidades (BRASIL, 2020b). Esta Resolução estabeleceu novas diretrizes e normas para a oferta dos cursos de PGLS no âmbito do Sistema Federal de Educação Superior. Entre elas destaca-se o reconhecimento da denominação "Especialização" para a pós-graduação Lato Sensu, o que até então já era utilizado no mercado, agora registrado em Resolução. Há de se destacar também o retorno dos credenciamentos especiais para oferta de cursos que, além das instituições de educação superior, os cursos de especialização poderão ser ofertados por outras instituições, conforme mencionado na introdução deste trabalho e no Art. $2^{\circ}$ da Resolução (BRASIL, 2020b). Quanto ao corpo docente, o Art. $9^{\circ}$ define reduz o percentual de professores portadores de título de pósgraduação Stricto Sensu para, no mínimo 30\% (trinta por cento), e a dispensa da realização do Trabalho de Conclusão de Curso, que nem sequer é citado na Resolução.

É possível perceber, portanto, que os cursos de PGLS gozam ainda de determinada autonomia e flexibilidade. Este fator facilitou a multiplicação de instituições sem qualificação ofertando essa formação, seja presencial ou a distância. Conforme se observa, há tentativas de se estabelecer normas para o acompanhamento desses cursos, mas a Resolução CNE/CES n ${ }^{\circ} 1$ de 2018 ampliou ainda mais o leque de instituições que podem oferecer esta modalidade de cursos. Desta forma, as ações até o momento foram inócuas e o setor acaba se esquivando das regras e buscando meios para manter e ampliar suas ofertas. Fonseca e Fonseca (2016) lamentaram ainda que o Plano Nacional de Pós-Graduação (PNPG) 2011-2020 restringiu-se apenas a regulamentar os cursos Stricto Sensu, desconsiderando novamente os cursos Lato Sensu.

\subsection{Critérios para Tomada de Decisão}

De fato, uma vez que um ponto chave desta formação é aumentar a qualificação do candidato, espera-se, portanto, que ela agregue valor à formação anterior. Assim, Nascimento et al. (2014) investigaram quais variáveis estavam relacionadas à tomada de decisão de 354 
estudantes na escolha de cursos de PGLS a distância, identificando que flexibilidade foi o fator determinante para tal escolha. Além disso, capacitação do corpo docente, proximidade do currículo ofertado com as atividades pedagógicas e custo foram outros critérios determinantes para a escolha do curso. Ishida, Stefano e Andrade (2013) também investigaram a satisfação no ensino de cursos à distância na visão de 72 alunos e 50 tutores. Os autores perceberam altos níveis de satisfação e indicaram preocupação em manter a qualidade de ensino dos cursos. A versatilidade do curso a distância foi um aspecto em destaque na visão dos alunos, enquanto conteúdo e objetivos do curso foram pontos positivos para tutores.

Níveis de preço, aspectos funcionais e emocionais e valor percebido foram dimensões estudadas por Panizzon et al. (2013) que investigaram a percepção da imagem de preço de serviço sobre as intenções de recompra para 159 estudantes de PGLS de uma universidade privada. Os resultados revelaram que as dimensões funcionais e valor percebido foram as mais significativas. Além disso, foram identificadas diferenças no conforto e aceitabilidade entre início e final de curso.

A tomada de decisão quanto a um curso de PGLS é baseada em diversos fatores, conforme expuseram Panizzon et al. (2013), Ishida, Stefano e Andrade (2013), Nascimento et al. (2014). Neste aspecto, destaca-se a necessidade de avaliar as expectativas de potenciais candidatos a um curso de Especialização ou MBA. Este trabalho aproveita esta oportunidade em busca de delinear o público-alvo para esta formação e dar possibilidade de outros pesquisadores, IES e empresas continuarem esta investigação.

\section{METODOLOGIA DE PESQUISA}

\subsection{Tipo de Pesquisa}

Esta pesquisa pode ser caracterizada como Pesquisa Aplicada Descritiva (PRESSER; SCHUMAN, 1981; CERVO, 2007). Sua natureza de pesquisa aplicada é a geração de conhecimentos aplicados focados em problemas específicos e o objetivo descritivo foca em investigar o perfil e expectativas de candidatos a cursos de PGLS. De acordo com os autores antes mencionados, este tipo de abordagem permite mensurar e analisar, inclusive quantitativamente, o nível de satisfação dos entrevistados, transformando uma medida subjetiva em outra de caráter numérico. 
ALVES, M. A.; CARVALHAES, C. L.; SOUSA, P. R. de. Pós-graduação Lato Sensu: apontamentos para a gestão estratégica a partir das expectativas dos candidatos

\subsection{Método de Coleta de Dados}

A primeira etapa consistiu na personalização do questionário, inspirando-se em Hortale e Moreira (2008), Hortale et al. (2010), Oliveira, Amâncio Filho e Pinto (2014), Brasil (2015a), Lemos Filho et al. (2015), Bastos e Rovaris (2016) e Correa e Alves (2018), sendo dividido, subjetivamente, em duas partes: fatores demográficos e fatores vinculados às expectativas dos candidatos. A primeira parte refere-se ao contexto geral do entrevistado, como: idade, formação, tempo e área de formação, entre outros. A segunda parte do questionário, descrita no Quadro 1, foi dividida em: questões relacionadas ao curso e sua ementa, motivos para tomada de decisão e atributos diversos.

\begin{tabular}{|c|l|}
\hline ID & \multicolumn{1}{|c|}{ Descrição } \\
\hline Expectativa em relação a cada item abaixo \\
\hline Q1 & Flexibilidade do curso / horário \\
\hline Q2 & Composição e Networking com os Professores \\
\hline Q3 & Currículo do curso integrar conteúdos de diferentes disciplinas \\
\hline Q4 & Metodologias de ensino utilizadas \\
\hline Q5 & Uso de tecnologias e sistemas de informação \\
\hline Q6 & Interação e participação dos alunos em sala de aula \\
\hline Q7 & Contribuição do curso para a sua formação teórica e profissional \\
\hline Q8 & Contextualização do conhecimento com temas gerais e situações do cotidiano \\
\hline Motivos para cursar pós-graduação Lato Sensu \\
\hline Q9 & Iniciativa Pessoal \\
\hline Q10 & Recomendação da instituição que trabalho, como aprimoramento \\
\hline Q11 & Pretendo continuar exercendo as mesmas atividades profissionais de forma mais aprimorada \\
\hline Q12 & Passar a exercer outras atividades relacionadas com a nova formação \\
\hline Importância de cada atributo para escolha do curso \\
\hline Q13 & Custo total do curso \\
\hline Q14 & Acessibilidade às instalações da instituição de ensino \\
\hline Q15 & Indicação boca-a-boca \\
\hline Q16 & Tradição da instituição \\
\hline Q17 & Preços promocionais / desconto adquirido \\
\hline & \\
\hline
\end{tabular}

ForScience, Formiga, v. 8, n. 2, e00858, jul./dez. 2020. 
Os entrevistados, ao responderem, avaliavam a importância de cada questão e externavam suas opiniões em notas em escala Likert de 1 a 9 pontos. Quanto mais próximo da nota 1 , menor a expectativa do entrevistado e quanto mais próximo de 9 , maior a expectativa. Além disto, optou-se por uma escala Likert superior a 5 pontos para evitar o viés da resposta central e por apresentar bons resultados quanto a obtenção de respostas (DALMORO; VIEIRA, 2013). Buscou-se, também, manter neutralidade nas perguntas para evitar viés aquiescente, apresentado por Schuman (1981).

A segunda etapa foi a aplicação do questionário a um público específico e posterior análise dos resultados. A aplicação de questionários pode ser considerada como uma técnica prospectiva e pode ser aplicada a um grande número de usuários ao mesmo tempo (FREITAS et al., 2000). Devido à dificuldade em identificar este público-alvo, aproveitou-se da oportunidade de um ciclo de palestras oferecido pela Pontifícia Universidade Católica de Minas Gerais (PUC Minas), cujo objetivo foi apresentar informações aos presentes quanto aos cursos de Especialização e MBA que seriam oferecidos pela Universidade. Por isso, compreende-se que os participantes atendiam aos requisitos para essa formação, o que viabilizou esta pesquisa.

Dentre todas as respostas obtidas, as seguintes foram desconsideradas: a) sem respostas na parte inicial (dados demográficos), b) todas as respostas como "Não aplicável”, visto que elas não traziam nenhum valor à pesquisa e c) duas ou mais respostas na mesma pergunta. Os dados foram tabulados e analisados no software estatístico R, por meio da interface RStudio versão 1.1.453.

\section{RESULTADOS E DISCUSSÃO}

\subsection{Confiabilidade do Questionário e Características dos Candidatos}

O questionário utilizado é uma adaptação da literatura e, por isso, decidiu-se mensurar sua fiabilidade por meio do coeficiente alfa de Cronbach. O resultado normalizado foi um valor igual a 0.86, superior a 0.7 que é requerido na literatura (STREINER, 2003). Portanto, sua consistência interna é satisfatória.

Foram obtidas 136 respostas válidas. Valendo-se da análise descritiva dos dados, constatou-se que o público-alvo interessado em iniciar uma PGLS nas áreas de Ciências Exatas e da Terra (34 entrevistados), Engenharias (51 entrevistados), Ciências da Saúde (27 entrevistados), Ciências Sociais Aplicadas (12 entrevistados) e Ciências Humanas (12 
ALVES, M. A.; CARVALHAES, C. L.; SOUSA, P. R. de. Pós-graduação Lato Sensu: apontamentos para a gestão estratégica a partir das expectativas dos candidatos

entrevistados) apresentam o seguinte perfil: gênero masculino (61.03\%), solteiro (61.03\%), idade entre 20 e 29 anos (49.26\%), provenientes de cursos superiores de graduação $(94.11 \%)$ concluídos até 2011 , sendo $26.47 \%$ entre 2016 e 2015 e $37.50 \%$ entre 2011 e 2014 . Eles graduaram em IES privadas (75.00\%), não cursaram Especialização (66.18\%), com atividade remunerada no setor privado (53.68\%) e tempo de serviço menor que 5 anos.

A faixa etária entre 20 e 29 anos está de acordo com a pesquisa de Nascimento et al. (2014) que revelaram a idade dos indivíduos que buscam um curso Lato Sensu presencial é inferior àqueles que buscam um curso a distância (observado como 36 anos de média). Entre os entrevistados, 66.18\% não cursaram especialização anteriormente. Os demais, $33.82 \%$, configuraram como egressos e com interesse em retornar ao meio acadêmico para nova formação. Dos 136 entrevistados, 30.88\%, a maioria, fizeram uma especialização presencial. Este valor indica a baixa aderência do grupo pesquisado a cursos Lato Sensu a distância, mostrando que, conforme destacaram Cunha et al. (2007), investigar o papel do egresso é fundamental para entendimento da qualidade do curso ofertado. Além disso, satisfazer suas expectativas pode representar uma boa forma de investimento, considerando o seu retorno a instituição para nova formação.

\subsection{Expectativas dos Candidatos}

Os três grupos de perguntas feitas no questionário estão ilustradas na Figura 1. Entre todos os entrevistados, a expectativa da contribuição do curso para a formação teórica $e$ profissional (Q7) possui alto grau de importância. Esta constatação havia sido indicada anteriormente, visto que os candidatos buscam essa formação como forma de verticalizar conhecimento e agregar valor à formação, vide Pilati (2006), Pires e Puggian (2014) e Fonseca e Fonseca (2016). Além disso, a maior parte deste público busca a PGLS por iniciativa própria (Q9), traduzindo a baixa recomendação pelas organizações as quais trabalham (Q10). Diferente da constatação de Nascimento et al. (2014), flexibilidade do curso (Q1) obteve baixo grau de importância. Todavia, entendeu-se que como os cursos oferecidos pela PUC Minas e apresentados nas palestras eram presenciais, esta variável pode estar enviesada. Flexibilidade do curso $(\mathrm{Q} 1)$, recomendação pela instituição em que trabalha $(\mathrm{Q} 10)$, pretender exercer as mesmas atividades de forma mais aprimorada (Q11) e indicação boca-a-boca (Q15) foram as variáveis com a mediana representando as menores notas (7, 6, 7 e 7 pontos, respectivamente). Além disso, todas as questões, exceto Q11, são assimétricas, com poucos ou nenhum valor 
espúrio. Q10 apresentou a maior variabilidade dos dados, que se concentraram entre as notas 1 e 7 pontos.

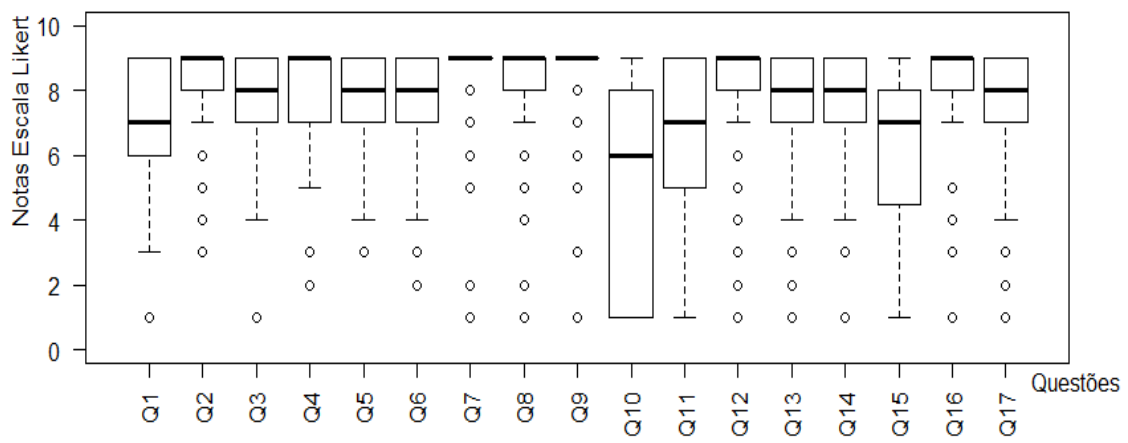

Figura 1 - Importância dos fatores avaliados, considerando questões voltadas ao curso e à ementa (Q1-Q8), motivos para cursar uma PGLS (Q9-Q12) e fatores diversos (Q13-Q17)

Fonte: Autores (2020).

Flexibilidade do curso (Q1) foi apontada como menos importante que outras variáveis deste primeiro grupo (Q1-Q8). A mediana variou entre 6 e 8 pontos, com intervalo interquartil de até 3 pontos. Como os cursos oferecidos pela universidade na época da coleta de dados eram todos presenciais, entende-se que esta variável pode refletir menor importância perante as demais. Todavia, ela se faz interessante em cursos que envolvem disciplinas a distância ou totalmente virtuais, conforme investigaram Ishida, Stefano e Andrade (2013) e Nascimento et al. (2014). De Q2 a Q8 os dados se mostraram com altos escores. Isso demonstra que existe alto grau de expectativa dos candidatos para questões de composição e relacionamento com professores $(\mathrm{Q} 2)$, currículo integrar diferentes disciplinas $(\mathrm{Q} 3)$, metodologias utilizadas $(\mathrm{Q} 4)$, uso das TICs (Q5), interação e participação dos alunos (Q6), contribuição do curso para formação teórica e profissional (Q7) e contextualização do curso com diversas situações (Q8). Samways Filho (2003) alertou as IES para que busquem conhecer a percepção do estudante pós-graduando, especialmente nos meses iniciais do curso, para evitar a evasão nesta fase.

A maior parte dos entrevistados buscam qualificação por iniciativa pessoal (Q9). Os dados estão concentrados nas mais altas notas e possuem baixa variação. Este apontamento está de acordo com as pesquisas de Fonseca (2004), Pilati (2006) e Cunha et al. (2007) que indicaram a busca por verticalização na carreira pelos candidatos que buscam um curso de pósgraduação. Este aperfeiçoamento também é refletido nas questões Q11 e Q12. A primeira diz respeito aos candidatos que pretendem continuar exercendo as mesmas atividades de forma mais eficiente. A segunda para aqueles que buscam executar novas atividades. Note que Q12 obteve maiores escores e menos variabilidade nas respostas, com baixo intervalo interquartil. 
ALVES, M. A.; CARVALHAES, C. L.; SOUSA, P. R. de. Pós-graduação Lato Sensu: apontamentos para a gestão estratégica a partir das expectativas dos candidatos

As questões Q10 e Q11 apresentaram maior variabilidade dos dados comparadas às demais. Q10 representa a pouca recomendação das empresas para que o candidato busque uma especialização.

Custo do curso (Q13), acessibilidade à IES (Q14), indicação boca-a-boca (Q15), tradição (Q16) e preços promocionais e descontos (Q17) formam o último grupo de perguntas. Custo obteve a maior parte das respostas com importância igual ou superior a 8 pontos. Tradição da universidade obteve um alto grau de importância e pouca variabilidade nas respostas, todavia acredita-se que elas podem relacionar-se à PUC Minas, local de aplicação do questionário.

A questão Q15 diz respeito às indicações feitas por outras pessoas para aquele determinado curso, retomando o discurso sobre a preocupação com as expectativas dos alunos durante a formação. Assim, os egressos podem fornecer indicações de curso e instituição e, quiçá, voltar a fazer um novo curso. Cunha et al. (2007) enfatiza o papel do egresso e sua importância para entender a qualidade dos cursos. Além disso, vale lembrar que entre os 136 entrevistados nesta pesquisa, 33.82\% são egressos de cursos Lato Sensu e com interesse em retornar ao meio acadêmico para nova formação.

\subsection{Gestão Acadêmica Estratégica}

Para fazer proposições quanto a estratégias de gestão dos cursos PGLS, as questões com nota média igual ou superior a 8 pontos foram consideradas por representarem as maiores expectativas. Todavia, vale ressaltar que esta nota pode variar dependendo do contexto da instituição e da necessidade de análise. O Quadro 2 traz uma breve análise sobre a gestão dos cursos de PGLS e indica ao gestor estratégico como lidar com estes fatores.

\begin{tabular}{|c|l|l|}
\hline ID & \multicolumn{1}{|c|}{ Descrição } & \multicolumn{1}{c|}{ Proposições } \\
\hline Q2 & $\begin{array}{l}\text { Composição e } \\
\text { Networking com os } \\
\text { Professores }\end{array}$ & $\begin{array}{l}\text { - Não repetir professores para a mesma turma, visando melhor } \\
\text { troca de experiências; } \\
\text { - Formar o corpo docente qualificado com experiência acadêmica e } \\
\text { mercadológica; } \\
\text { - Trazer docentes com experiência em empresas de segmentos } \\
\text { diferentes. }\end{array}$ \\
\hline Q3 & $\begin{array}{l}\text { Currículo do curso } \\
\text { integrar conteúdos de } \\
\text { diferentes disciplinas }\end{array}$ & $\begin{array}{l}\text { - Oferecer disciplinas comuns para cursos de mesma área; } \\
\text { - Grade curricular atualizada com o mercado e academia; }\end{array}$ \\
\hline
\end{tabular}




\begin{tabular}{|c|c|c|}
\hline Q4 & $\begin{array}{l}\text { Metodologias de ensino } \\
\text { utilizadas }\end{array}$ & $\begin{array}{l}\text { - Investigar novos modelos de aprendizagem, como o Problem } \\
\text { Based Learning }(P B L) \text {; } \\
\text { - Treinamentos com o corpo docente de forma a capacitar para o } \\
\text { uso de novas TICs; }\end{array}$ \\
\hline Q5 & $\begin{array}{l}\text { Uso de tecnologias e } \\
\text { sistemas de informação }\end{array}$ & $\begin{array}{l}\text { - Investimento em plataformas de ensino, como por exemplo: LMS } \\
\text { - Learning Management System; } \\
\text { - Ludificação no processo de aprendizagem. }\end{array}$ \\
\hline Q6 & $\begin{array}{l}\text { Interação e participação } \\
\text { dos alunos em sala de } \\
\text { aula }\end{array}$ & $\begin{array}{l}\text { - Fomentar discussão de problemas práticos; } \\
\text { - Promover debates através de eventos e seminários com } \\
\text { profissionais de mercado e acadêmicos sobre temas atuais. }\end{array}$ \\
\hline Q7 & $\begin{array}{l}\text { Contribuição do curso } \\
\text { para a sua formação } \\
\text { teórica e profissional }\end{array}$ & $\begin{array}{l}\text { - Promover a interação entre a IES e empresas; } \\
\text { - Buscar autorização para promover o curso com instituições } \\
\text { certificadoras e entidades de classe. }\end{array}$ \\
\hline Q8 & $\begin{array}{l}\text { Contextualização do } \\
\text { conhecimento com } \\
\text { temas gerais e situações } \\
\text { do cotidiano }\end{array}$ & $\begin{array}{l}\text { - Trazer problemas que os alunos vivenciam nas empresas para } \\
\text { debates em salas de aula; } \\
\text { - Explorar debates que estejam em evidência no cenário midiático; } \\
\text { - Propor aos professores apresentarem exemplos práticos e reais do } \\
\text { cotidiano. }\end{array}$ \\
\hline Q9 & Iniciativa Pessoal & $\begin{array}{l}\text { - Investir nos canais de comunicação e campanhas publicitárias } \\
\text { para atrair o interessado; } \\
\text { - Associar políticas de benefícios para ex-alunos, descontos, mini- } \\
\text { cursos, livros etc; } \\
\text { - Parcerias com entidades de classe e conselhos para divulgação e } \\
\text { creditação do curso. }\end{array}$ \\
\hline Q12 & $\begin{array}{l}\text { Passar a exercer outras } \\
\text { atividades relacionadas } \\
\text { com a nova formação }\end{array}$ & $\begin{array}{l}\text { - Explorar atividades práticas e troca de experiências durante o } \\
\text { curso, buscando uma formação sólida em determinado campo do } \\
\text { saber ao mesmo tempo que fornece uma visão generalista sobre } \\
\text { outros temas. }\end{array}$ \\
\hline Q13 & Custo total do curso & $\begin{array}{l}\text { - Parcelamento maior para pagamento das mensalidades; } \\
\text { - Descontos para matrículas até determinadas datas; } \\
\text { - Analisar a viabilidade em oferecer determinadas disciplinas a } \\
\text { distância, pois minimizam os custos operacionais e deslocamentos; } \\
\text { - Mix de turmas para disciplinas com ementas equivalentes. }\end{array}$ \\
\hline Q14 & $\begin{array}{l}\text { Acessibilidade às } \\
\text { instalações da } \\
\text { instituição de ensino }\end{array}$ & $\begin{array}{l}\text { - Posicionamento geográfico estratégico; } \\
\text { - Oferecer parcerias e conveniências com serviços em torno da } \\
\text { instituição de ensino; } \\
\text { - Disponibilizar recursos humanos e infra-estrutura física para } \\
\text { atender ao público com necessidades especiais. }\end{array}$ \\
\hline Q16 & Tradição da instituição & $\begin{array}{l}\text { - Entende-se por tradição a confiança depositada na instituição ao } \\
\text { longo dos anos. Portanto, as IES com tradição no mercado devem } \\
\text { explorar esta característica em suas campanhas. As demais podem } \\
\text { focar em apresentar seus pontos fortes de forma a atrair e reter } \\
\text { novos alunos. }\end{array}$ \\
\hline Q17 & $\begin{array}{l}\text { Preços promocionais / } \\
\text { desconto adquirido }\end{array}$ & $\begin{array}{l}\text { - Campanhas para nichos específicos, como descontos para ex- } \\
\text { alunos de graduação e especialização; } \\
\text { - Parcerias com empresas, aos quais potencializa as oportunidades } \\
\text { de atrair novos alunos. }\end{array}$ \\
\hline
\end{tabular}

Quadro 2 - Critérios avaliados e medidas propostas para a gestão acadêmica estratégica Fonte: Autores (2020). 
ALVES, M. A.; CARVALHAES, C. L.; SOUSA, P. R. de. Pós-graduação Lato Sensu: apontamentos para a gestão estratégica a partir das expectativas dos candidatos

É possível observar uma relação intrínseca entre muitos critérios. Este indicativo permite fazer proposições de forma que haja múltiplos ganhos. Por exemplo, o desconto oferecido a um ex-aluno (Q17), por minimizar o custo total do curso (Q13) pode incentivá-lo a regressar aos estudos para uma nova formação e consequente aumento nos resultados da IES. Como verificado nos resultados desta pesquisa, 33.82\% dos entrevistados se configuram egressos. Além disso, conforme destacado anteriormente por Cunha et al. (2007) os egressos desempenham um papel importante na avaliação da instituição e são potenciais candidatos a um novo curso.

O contexto de mercado se configura um ponto estratégico para as IES. Notou-se que os candidatos buscam uma nova formação por iniciativa pessoal (Q9) almejando verticalização na carreira (Q3, Q7, Q12). Fonseca (2004), Pilati (2006) e Cunha et al. (2007) destacaram o anseio dos candidatos por impulsionar a carreira e se destacarem no mercado. Assim, o curso Lato Sensu deve fornecer conhecimento e habilidade que a graduação somente não supriu. Além disso, a possibilidade de interação entre alunos e professores se mostrou muito importante nesta pesquisa (Q2). O candidato que deseja mudar de área deseja quer potencializar a qualificação vislumbrando possibilidades de interação com professores experientes e profissionais de mercado inseridos naquela área. Outrossim, o modelo de disciplinas se mostrou um importante fator a ser considerado (Q3, Q4), embora possa ser investigado se o formato adotado pode ser alterado para beneficiar outros fatores, como minimizar os custos do curso (Q13).

Conquanto os resultados indicam algumas variáveis avaliadas com menor importância, elas também devem ser consideradas na análise estratégica. Como os objetivos e metas estabelecidas varia entre as instituições, o gestor estratégico deve estar atento de ocorrer que alguma sugestão já esteja sendo implementada. Entende-se também que algumas medidas propostas não dependem apenas de um planejamento ou mesmo ação, mas sim de uma discussão orçamentária junto à administração superior da IES.

\section{CONSIDERAÇÕES FINAIS}

Esta pesquisa centrou-se em identificar e mensurar as características e expectativas de candidatos a cursos de Pós-Graduação Lato Sensu. Por meio de um questionário validado, identificaram-se pontos de atenção considerando a média das notas obtidas. O perfil dos entrevistados foi predominantemente do gênero masculino, solteiro, idade entre 20 e 29 anos, 
provenientes de cursos superiores de graduação concluído até 2011 e nota-se, portanto, um perfil marcado por pessoas mais jovens e com baixo tempo de graduação. Entre eles, 75\% cursaram graduação em IES privadas. Associa-se neste ponto que muitas instituições privadas de ensino têm perfil de formação mais voltado para o mercado de trabalho e com baixo incentivo a pesquisa. Outro ponto comumente destacado na literatura é que as IES privadas, especialmente os cursos noturnos, concentram-se as turmas com candidatos já efetivados no mercado de trabalho, que por sua vez buscam ascensão na carreira. Os dados coletados retratam este indicativo, uma vez que $79.66 \%$ dos entrevistados exercem atividade remunerada no setor privado ou público e têm tempo de serviço inferior a 5 anos (53.68\%).

As expectativas dos candidatos se mostraram elevadas, especialmente com questões relacionadas à contribuição do curso para formação teórica e profissional. A maioria dos entrevistados busca o curso por iniciativa pessoal e desejam exercer novas atividades de acordo com a formação. Flexibilidade do curso, recomendação da instituição que os entrevistados trabalham continuar exercendo as mesmas atividades e indicação boca-a-boca foram as variáveis com maior variabilidade nas respostas. E também com as menores medianas. As demais, comumente igual ou superior a 8 pontos, traduzem o alto grau de importância depositadas nestas questões quanto ao curso pretendido.

Contribuição do curso para a formação teórica e profissional e decisão de buscar o curso por iniciativa pessoal foram as questões com maior importância. Nota-se que os resultados da primeira questão estão de acordo com as pesquisas da literatura, as quais indicaram o desejo por verticalização na carreira e destaque mercadológico. Iniciativa pessoal indica a baixa influência das empresas sobre o percurso de formação dos candidatos. É interessante verificar a autonomia dos candidatos em relação à sua própria formação uma vez que as empresas, as quais vão recebê-los, não participam ou indicam o percurso formativo desejável. Se por um lado os candidatos detêm o desejo pela formação por iniciativa pessoal, por outro perde a oportunidade de conhecer as demandas do mercado.

O presente artigo indica as expectativas quanto a algumas variáveis que os estudantes de um curso de PGLS consideram em sua formação. É fortemente recomendado aos gestores estratégicos que as proposições estejam alinhadas com as metas e à realidade da instituição. Entende-se que ações isoladas podem trazer algum benefício a curto prazo, mas podem não ser satisfatórias a médio e longo prazo. Os desafios desta pesquisa também geram oportunidades para novas, como conseguir um número significativo de respostas e englobar candidatos de outras instituições, quando possível. 
Os resultados deste trabalho abrem possibilidades para novas pesquisas e serve como guia para a comunidade acadêmica e instituições interessadas em investigar os cursos de PósGraduação Lato Sensu. Este estudo auxilia no entendimento das características dos candidatos e aponta expectativas quanto aos cursos de Especialização e MBA. Estas evidências abrem portas para campanhas e ações sobre tais variáveis pelas instituições de educação superior na promoção e oferta dos cursos.

\section{REFERÊNCIAS}

BASTOS, C. C. B. C.; ROVARIS, N. A. Z. A relevância do processo de autoavaliação institucional da universidade tecnológica para a configuração do bom professor. Avaliação: Revista da Avaliação da Educação Superior, Campinas, v. 21, n. 3, p. 767-781, 2016.

BRASIL. Ministério da Educação/INEP - Instituto Nacional de Estudos e Pesquisas Educacionais Anísio Teixeira. Questionário do Estudante 2015. Brasília: Inep, 2015, 8 p.

BRASIL. Ministério da Educação. Conselho Nacional de Educação. Câmara de Educação Superior. Resolução ${ }^{\circ} 1$, de 8 de junho de 2007 . Estabelece normas para o funcionamento de cursos de pós-graduação Lato Sensu, em nível de especialização. Brasília: MEC/CNE/CES, 2015.

BRASIL. Ministério da Educação. Lato-Sensu - saiba mais. Disponível em: http://portal.mec.gov.br/pos-graduacao/pos-lato-sensu. Acesso em: 22 jun. 2020.

BRASIL. Ministério da Educação/Capes. Conselho Nacional de Educação. Resolução CNE/CES, n. 01, de 2001. Autorização e credenciamento dos cursos de pós-graduação Stricto Sensu; funcionamento dos cursos de pós-graduação Lato Sensu. Brasília: MEC/CNE/CES, 2001.

BRASIL. Ministério da Educação/I INEP - Instituto Nacional de Estudos e Pesquisas Educacionais Anisio Teixeira. Censo da Educação Superior. Brasília: Inep, 2003, 47 p.

BRASIL. Ministério da Educação. Conselho Nacional de Educação. Câmara de Educação Superior. Resolução $\mathbf{n}^{\mathbf{0}} \mathbf{2}$, de 12 de fevereiro de 2014. Institui o cadastro nacional de oferta de cursos de pós-graduação Lato Sensu (especialização) das instituições credenciadas no Sistema Federal de Ensino. Brasília: MEC/CNE/CES, 2014.

BRASIL. Ministério da Educação. Pós-Graduação - normativos. Disponível em: http://portal.mec.gov.br/pro-conselho/323-secretarias-112877938/orgaos-vinculados82187207/12899-pos-graduação-normativos. Acesso em: 22 jun. 2020.

BRASIL. Ministério da Educação. Conselho Nacional de Educação. Câmara de Educação Superior. Resolução $\mathbf{n}^{\mathbf{0}}$ 1, de 06 de abril de 2018. Estabelece diretrizes e normas para a oferta dos cursos de pós-graduação Lato Sensu denominados cursos de especialização, no 
ALVES, M. A.; CARVALHAES, C. L.; SOUSA, P. R. de. Pós-graduação Lato Sensu: apontamentos para a gestão estratégica a partir das expectativas dos candidatos

âmbito do Sistema Federal de Educação Superior, conforme prevê o Art. 39, § $3^{\circ}$, da Lei no 9.394/1996, e dá outras providências. Brasília, DF: MEC/CNE/CES, 2018.

CERVO, A. L. Metodologia científica. 6 ed. São Paulo: Pearson Prentice Hall, 2007.

CORREA, R. C.; ALVES, M. A. Análise das expectativas dos candidatos a cursos de pósgraduação Lato Sensu. In: SEMINÁRIO DE PESQUISA E INOVAÇÃO, 2., 2008, Formiga. Anais [...]. Formiga: IFMG - Campus Formiga. Anais eletrônicos[...]. 2018, Formiga, Minas Gerais.

CUNHA, I. C. K. O. et al. Construindo instrumentos de avaliação para os cursos de pósgraduação Lato Sensu da Unifesp: relato de experiência. Estudos em Avaliação

Educacional, São Paulo, v. 18, n. 38, p. 29-40, 2007.

DALMORO, M.; VIEIRA, K. M. Dilemas na construção de escalas Tipo Likert: o número de itens e a disposição influenciam nos resultados? Revista Gestão Organizacional, Chapecó, v. 6, n. 3, p. 161-174, 2013.

FONSECA, D. M. Contribuições ao debate da pós-graduação Lato Sensu. Revista Brasileira de Pós-Graduação, Brasília, v. 1, n. 2, p. 173-182, 2004.

FONSECA, M.; FONSECA, D. M. A gestão acadêmica na pós-graduação Lato Sensu: o papel do coordenador para a qualidade dos cursos. Educação e Pesquisa, São Paulo, v. 42, n. 1, p. 151-164. 2016.

FREITAS, M. A. O.; CUNHA, I. C. K. O. Pós-graduação Lato Sensu: retrospectiva histórica e política atual. In: CONGRESSO NACIONAL DE EDUCAÇÃO, 9., 2009, Curitiba.

Anais[...]. Curitiba. p. 975-982.

FREITAS, H. et al. O método de pesquisa survey. Revista de Administração da USP RAUSP, São Paulo, v. 35, n. 3, p. 105-112, 2000.

ISHIDA, J. S.; STEFANO, S. R.; ANDRADE, S. M. Avaliação da satisfação no ensino de pós à distância: a visão dos tutores e alunos do PNAP/UAB. Avaliação: Revista da Avaliação da Educação Superior, Campinas, v. 18, n. 3, p. 749-772, 2013.

HORTALE, V. A.; MOREIRA, C. O. F. Auto-avaliação nos programas de pós-graduação na área da saúde coletiva: características e limitações. Ciência \& Saúde Coletiva, Rio de Janeiro, v. 13, n. 1, p. 223-233, 2008.

HORTALE, V. A. et al. Características e limites do mestrado profissional na área da saúde: estudo com egressos da Fundação Oswaldo Cruz. Ciência \& Saúde Coletiva, Rio de Janeiro, v. 15, n. 4, p. 2051-2058, 2010.

LEMOS FILHO, A. et al. Avaliação do ensino: modelo de análise da série histórica de resultados. Avaliação: Revista da Avaliação da Educação Superior, Campinas, v. 21, n. 1, p. 221-245, 2015. 
MAZON, G. et al. O uso de metodologia multicritério em apoio à decisão construtivista para avaliar o desempenho do programa de cursos de pós-graduação Lato Sensu. Revista

Economia e Gestão, Belo Horizonte, v. 12, n. 28, p. 30-52, 2012.

NASCIMENTO, E. M. et al. Variáveis que influenciam a escolha dos estudantes por cursos de pós-graduação Lato Sensu a distância na área de negócios. Revista de Educação e

Pesquisa em Contabilidade, Brasília, v. 8, n. 1, 2014.

OLIVEIRA, F. B. Pós-graduação: educação e mercado de trabalho. Papirus, Campinas, 1995.

OLIVEIRA, S. P.; AMÂNCIO FILHO, A.; PINTO, I. V. Características e expectativas dos inscritos no processo seletivo do mestrado profissional em Gestão do Trabalho e da Educação na Saúde. Revista Brasileira de Pós-Graduação, Brasília, v. 11, n. 24, p. 589 - 603, 2014.

PANIZZON, M. et al. A percepção da imagem de preço em serviços: um estudo de abordagem quantitativa sobre os cursos de Lato Sensu de uma Universidade. Revista Eletrônica de Administração, Porto Alegre, v. 19, n. 3, p. 646-674, 2013.

PILATI, Orlando. Especialização: falácia ou conhecimento aprofundado? Revista Brasileira de Pós-Graduação, Brasília, v. 3, n. 5, p. 7-26, 2006.

PIRES, N.; PUGGIAN, C. Pós-graduação Lato Sensu: legislação atual, novas diretrizes e a experiência da UNIGRANRIO. Almanaque Multidisciplinar de Pesquisa, Duque de Caxias, v. 1, n. 2, p. 13-29, 2014.

PRESSER S.; SCHUMAN, H., Questions and answers in attitude surveys: experiments on question form, wording, and context, Sage, San Diego, California, 1981.

ROMERO, L. D.; LOPES, K. G. Formação continuada e pós-graduação Lato Sensu: o caso da Universidade Estadual do Maranhão. In: CONGRESSO BRASILEIRO DE HISTÓRIA NA EDUCAÇÃO, 2., 2002, Natal. Anais[...]. Natal: CBHE, 2002, p. 1-10.

SAMWAYS FILHO, J. L. Percepções e ações sobre a pós-graduação Lato Sensu como fator regulador na qualidade do ensino superior. In: COLOQUIO INTERNACIONAL SOBRE GESTIÓN UNIVERSITARIA EM AMÉRICA DEL SUR, 3., 2003, Buenos Aires. Anais[...]. Buenos Aires, 2003, p. 1-18.

SPAGNOLO, F.; SEVILLA, M. A. F. A situação atual da pós-graduação Lato Sensu. Boletim Informativo, Teresina, v. 4, n. 3, p. 23-26, 1994.

STREINER, D. L. Beingin consistent about consistency: when coefficient alpha does and doesn't matter. Journal of Personality Assessment, v. 80, n. 3, p. 217-222, 2003.

\section{DADOS DOS AUTORES}

Nome: Marcos Antônio Alves

E-mail: m.voicer@gmail.com 
Curriculum Lattes: http://lattes.cnpq.br/4636940519958225

Doutorando (2018--) e Mestre (2016-2018) em Inteligência Computacional no Programa de Pós-Graduação em Engenharia Elétrica da Universidade Federal de Minas Gerais. Especialista em Gerenciamento de Projetos (2014) e bacharel em Sistemas de Informação (2010) pela Pontifícia Universidade Católica de Minas Gerais. Tem interesse em Machine Learning, Tomada de Decisão Multicritério, Lógica Fuzzy, Computação Evolucionária e Sistemas de Recomendação.

Nome: Cristiano Lopes Carvalhaes

E-mail: cristiano@pucminas.br

Curriculum Lattes: http://lattes.cnpq.br/6984475643117081

Mestrado em Administração com ênfase em Docência e Gestão da Educação pela Universidade Fernando Pessoa em Porto/Portugal; pós-graduação Lato Sensu em Gestão Financeira, MBA em Gestão de Negócios em Contexto Empreendedor e graduação em Administração pela Pontifícia Universidade Católica de Minas Gerais. Experiência em expertise na pós-graduação Lato Sensu, docência, coordenação e desenvolvimento de projetos. Consultor com atuação nas áreas de estratégia, finanças, inteligência de negócios e projetos educacionais diversos.

Nome: Paulo Roberto de Sousa

E-mail: p.roberto@pucminas.br

Curriculum Lattes: http://lattes.cnpq.br/1372327776293612

Mestrado em Engenharia de Produção pela Universidade Federal de Minas Gerais e graduação em Administração e Ciências Contábeis pela Pontifícia Universidade Católica de Minas Gerais. Professor Adjunto I da Pontifícia Universidade Católica de Minas Pontifícia Universidade Católica de Minas Gerais. Consultor do MEC. Chefe de Gabinete do Reitor da Pontifícia Universidade Católica de Minas Gerais. 